\title{
Glucosinolates, Degradation Products and Myrosinase Activity in Raphanus sativus Linn.
}

\author{
Maria Carmen S. Tan*, Marissa G. Noel
}

\section{Maria Carmen S. Tan*, Marissa G. Noel}

Chemistry Department, De La Salle University, 2401 Taft Avenue, Manila 1004. PHILIPPINES.

\section{Correspondence}

\section{Maria Carmen Tan}

Chemistry Department, De La Salle University, 2401 Taft Avenue, Manila 1004, PHILIPPINES.

Phone no: +632 5360230;

Fax: +632 5360230;

E-mail: maria.carmen.tan@dlsu.edu.ph

History

- Submission Date: 12-01-2019;

- Review completed: 30-04-2019.

- Accepted Date: 16-05-2019.

DOI : 10.5530/pj.2019.11.139

Article Available online

http://www.phcogj.com/v11/i5

\section{Copyright}

(C) 2019 Phcogj.Com. This is an openaccess article distributed under the terms of the Creative Commons Attribution 4.0 International license.

\section{ABSTRACT}

This research was conducted to assess the gluocosinolate (GSL), isothiocyanate (ITC) and myrosinase content in two cultivars of Raphanus sativus Linn. (white and red) roots. LC-ESIMS investigation was done on desulfated GSLs since this methodology has been previously established for efficient GSL analyses. The major GSLs: sinigrin (1) 1,2-dihydroxy-2-phenylethyl glucosinolate (2), 4-hydroxyglucobrassicin (3), glucoraphasatin (4) and 4-methoxyglucobrassicin (5) were found in red radishes; whereas, only $\mathbf{1}$ and $\mathbf{4}$ were obtained in white radishes. Myrosinase was analyzed in the tubers due to its ability to catalyze and hydrolyze GSLs into ITCs. This $\beta$-thioglucosidase enzyme was found to be over 10 times more active in red tubers (2.05E-02 units) than in white radishes (1.55E-03 units) and the results were linked to the presence/absence of the outer covering of the tubers. Due to the promising medicinal properties of the aglucone derivative of compound 4, 4-methylthio-3-butenyl isothiocyanate (6), the ITC analog was monitored using gas chromatographic mass spectral analyses after myrosinase-mediated hydrolysis. From the results, it can be construed that the occurrence of GSLs 1-5 and the bioactive agent 6 were inherent in the R. sativus cultivars evaluated. Key words: Glucosinolates, Isothiocyanates, Myrosinase, LC-ESI-MS, GC-MS, GC-FID.

\section{BACKGROUND}

The Philippines, with its vast wealth of medicinal herbal plants, has surprisingly the highest breast cancer incidence in Asia, as stipulated by Youlden, et al. ${ }^{1}$ Cruciferous vegetables, historically, are known to contain glucosinolates (GSLs), a group of sulfur containing metabolites with many medical properties. GLSs are $\beta$-thioglucoside $\mathrm{N}$-hydroxysulfates (also known as (Z)-(or cis)-Nhydroximinosulfate esters or S- glucopyranosyl thiohydroximates), with a side chain (R) and a sulfur-linked $\beta$-D-glucopyranose moiety, which was found by Tommaso, et al. ${ }^{2}$ Waser \& Watson ${ }^{3}$ reported the geometrical isomerism, as found by $\mathrm{Li}$, et $a l .{ }^{4}$ at the $\mathrm{CN}$ bond was established to be $\mathrm{Z}$ (or cis-) by X-ray crystallographic analysis of sinigrin. Five hundred species of non-cruciferous dicotyledonous angiosperms have been reported to contain one or more of the over 120 known GSLs. The skeleton of GSL consists of a thioglucosidic link to the carbon of a sulphonated oxime. The $\mathrm{R}$ group (side chain) and the sulfate group have anti stereochemical configuration. The side chain is derived from amino acids and is highly variable; it can be aliphatic aromatic or heterocyclic, as studied by Oerlemans, et al. ${ }^{5}$

GSLs, however, are only useful when hydrolyzed via the $\beta$-thioglucosidase, myrosinase which is stored in specialized vacuoles within the plant structure. GSLs yield a variety of compounds after hydrolysis depending on factors such as plant species and cultivar, site of hydrolysis, the presence of cofactors and environmental conditions. Tommaso, et al. ${ }^{2}$ stated that in the absence of myrosinase, as when plants are cooked and the enzyme is denatured, humans can still efficiently convert GSLs to ITCs through the action of the microflora present in the gastrointestinal tract. ${ }^{2}$

GSL 4, as divulged by Carlson, et al. ${ }^{6}$, has been shown to be present in the tubers of several radish varieties. Its hydrolysis product, the ITC $\mathbf{6}$, a compound reported to be capable of anti-microbial, antimutagenic and anti-carcinogenic activity, has been isolated from radish roots. ${ }^{4}$ Some ITCs have been found to protect normal cells from DNA damage and to induce malignant cancer cells to undergo apoptosis.

In the work, we have investigated the GSLs and possible hydrolysis products (Figure 1) of the cultivars of Raphanus sativus L., specifically the white $(\mathbf{W})$ and red $(\mathbf{R})$ varieties. To the best of our knowledge, this is the first reported extensive study using this methodology of analyses on the extracts of $R$. sativus $\mathrm{L}$

\section{PROCEDURE}

\section{Materials}

Certification that the mature tubers of several $R$. sativus varieties used in this study were of the same family and species was verified at the National Museum, Botany Division in Manila, Philippines. Extractions and analysis were done immediately to ensure reliability of results. Visual appearance and freedom from defects were considered in the selection of the samples for analyses.

\section{Sample preparation}

In accordance with common culinary practices, white radish tubers were washed and peeled before 


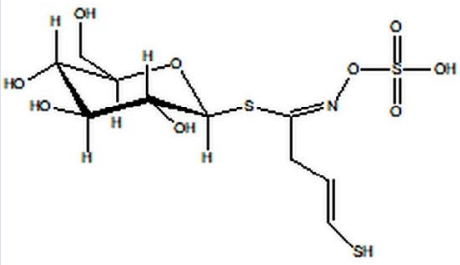

(1)

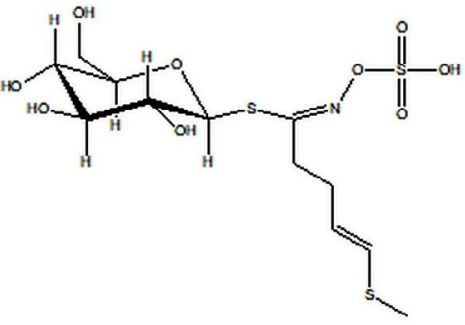

(4)

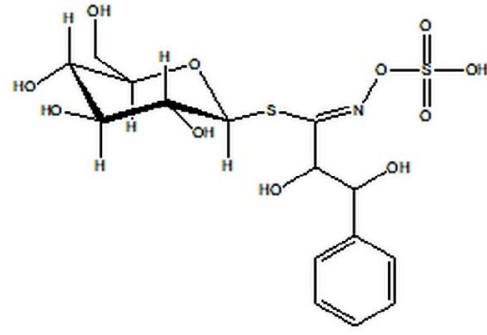

(2)

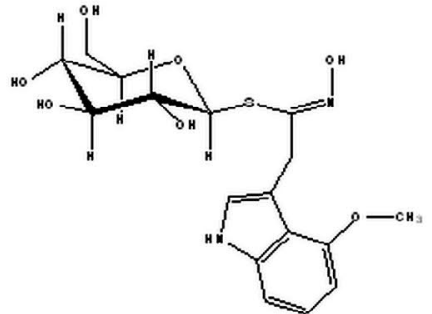

(5)

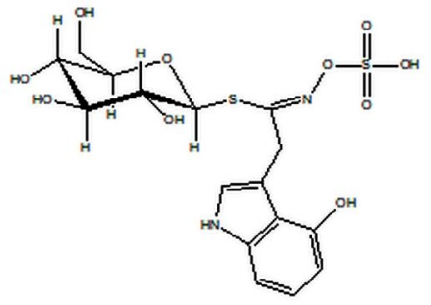

(3)

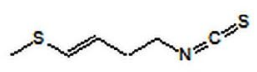

(6)

Figure 1: Chemical constituents found in R. sativus cultivars:sinigrin (1), 1,2-dihydroxy-2-phenylethylglucosinolate (2), 4-hydroxyglucobrassicin (3), glucoraphasatin (4), 4-methoxyglucobrassicin (5), 4-methylthio-3-butenyl isothiocyanate (6).

cutting into cubes and the red roots were washed and sliced thinly. The samples were then freeze-dried until sufficient drying was achieved. Lyophilized samples were then ground in a coffee grinder and analyzed for glucosinolate content, myrosinase activity and hydrolysis products.

\section{LC-ESI-QII-ToF- MS analysis of desulfoglucosinolates}

GSLs content was determined by high performance liquid chromatography of desulfoglucosinolates using a modified method patterned from Oerlemans, et al. ${ }^{5}$ The analyses were performed using an Agilent Technologies 1200 Series HPLC with an RPC18 $(250 \mathrm{~mm} x$

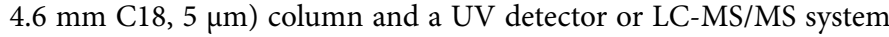
equipped with DIONEX Ultimate 3000 HPLC with an RPC18 column ( $150 \mathrm{~mm} \times 2.6 \mathrm{~mm}, 3 \mu \mathrm{m}, 120 \AA$ ) in tandem with a BrukermicrOTOF-Q II MS with an ESI source type set at a positive ion polarity with nitrogen as the nebulizer gas at 2.0 bar. The detector scan ranged from 50 to 1000 $\mathrm{m} / \mathrm{z}$ with the capillary at $4500 \mathrm{~V}$, end plate offset at $-500 \mathrm{~V}$, collision cell $\mathrm{RF}$ at $120.0 \mathrm{Vpp}$, dry heater at $200^{\circ} \mathrm{C}$ and the drying gas at $7.0 \mathrm{l} / \mathrm{min}$.

The solvent system for the gradient program consisted of $0.01 \%$ formic acid in distilled water (B) and acetonitrile (A) and was as follows: $100 \%$ $\mathrm{B}$ at $0-1 \mathrm{~min}$.; at 1-15 min. the gradient was from $100 \% \mathrm{~B}$ to $75 \% \mathrm{~B}$ and $25 \% \mathrm{~A}$; and $75 \% \mathrm{~B}$ and $25 \% \mathrm{~A}$ was maintained for $5 \mathrm{~min}$; from 20 to 25 min. the gradient was from $75 \% \mathrm{~B}$ and $25 \% \mathrm{~A}$ to $100 \% \mathrm{~B} ; 100 \% \mathrm{~B}$ was maintained for $1 \mathrm{~min}$. The UV detector, temperature and flow rate were set at $230 \mathrm{~nm}, 25^{\circ} \mathrm{C}$ and $0.300 \mathrm{~mL} / \mathrm{min}$, respectively.

\section{Determination of myrosinase activity}

The hydrolysis products produced are highly dependent on the action of the enzyme myrosinase on the GSLs. Bell, et al. ${ }^{7}$ stated that myrosinase causes deglycosylation of GSLs which then stimulates the aglycone to undergo a Lossen-like rearrangement to form an ITC. It was for this reason that an enzyme assay was performed to explain the formation of the bioactive ITC constituents.

Weighed samples were placed in a ceramic mortar and pestle and ground after adding $15 \mathrm{~mL}$ of cold deionized water. The resulting mixture was then filtered and the filtrate collected in a $50-\mathrm{mL}$ volumetric flask. The residue was extracted twice with $10 \mathrm{~mL}$ of water and filtered as before. The filtrates were combined and diluted to $50 \mathrm{~mL}$ The combined filtrates constituted the crude enzyme extract.

A $40 \mathrm{~mL}$ aliquot of the combined filtrates was centrifuged at 7000 $\mathrm{rpm}$ for $5 \mathrm{~min}$ at $4^{\circ} \mathrm{C}$. The supernatant was mixed with $15 \mathrm{~mL}$ cold acetone and incubated for $1.5 \mathrm{~min}$. After incubation, the solution was centrifuged and the precipitate collected. The precipitate was dissolved in $0.5 \mathrm{~mL} 3 \mathrm{mM}$ potassium phosphate buffer at $\mathrm{pH}$ 7. The enzyme solution underwent UV-Vis spectrophotometric analysis for myrosinase activity, using a modified procedure taken from Bellostas, et al. ${ }^{8}$ and Palmieri, et al. ${ }^{9}$ In a cuvette, $50 \mathrm{mM}$ phosphate buffer at $\mathrm{pH} 6.5,0.25$ $\mathrm{mM}$ ascorbic acid and $0.2 \mathrm{mM}$ sinigrin were combined. The absorbance of the reaction mixture was monitored at $227 \mathrm{~nm}$ for the presence of sinigrin. A measured amount of the prepared enzyme extract/solution was then added and the absorbance read at $227 \mathrm{~nm}$ after 5 min intervals for $90 \mathrm{~min}$. Analysis of myrosinase activity was carried out using a Hitachi UV-Vis double beam (U-2000) spectrophotometer.

\section{Gas chromatographic analysis of hydrolysis products}

Hydrolysis products were analyzed using an Agilent Technologies 7890A GC System in tandem with a 5977 MSD. The gas chromatograph was equipped with an HP - 5ms Ultra Inert column cross-linked 5\% diphenyl 95\% dimethylpolysiloxane ( $30 \mathrm{~m} \times 0.25 \mathrm{~m} \times 0.25 \mu \mathrm{m})$ with helium as the carrier gas. The temperature program started at $50^{\circ} \mathrm{C}$ with a ramp of $5^{\circ} \mathrm{C}$ per minute to a final temperature of $280^{\circ} \mathrm{C}$ which was held for two minutes. The injection inlet and the MSD transfer line were held at $250^{\circ} \mathrm{C}$ and $280^{\circ} \mathrm{C}$, respectively. The column flow was set at $1.1 \mathrm{~mL} / \mathrm{min}$, the pressure held at $8.3 \mathrm{psi}$, the average velocity at $37.5 \mathrm{~cm} / \mathrm{s}$ and the holdup time at $1.333 \mathrm{~min}$. The detector scan time segment began at 4 min with electron ionization mass spectra acquired from $50 \mathrm{~m} / \mathrm{z}$ to $550 \mathrm{~m} / \mathrm{z}$ at a frequency of 2.9 scans/s, a cycle of $342.63 \mathrm{~ms}$ and a step size of $0.1 \mathrm{~m} / \mathrm{z}$. 
Chromatographic analysis of extracts obtained following each method revealed that hydrolysis of undefatted samples produced the best results. The hydrolysis procedure involved the addition of $10 \mathrm{~mL}$ deionized water and $5 \mu \mathrm{L}$ myrosinase $(3 \mathrm{U} / \mathrm{mL})$ to 1 gram of freezedried sample followed by incubation of the reaction mixture for $1 \mathrm{hr}$ at room temperature. Measured quantities of lyophilized hydrolyzates were extracted with a low boiling solvent (dichloromethane) and the mixture was then centrifuged. The residue was re-extracted twice using the same conditions, after which the supernatants were combined then passed through an anhydrous sodium sulfate column and concentrated over nitrogen $\left(\mathrm{N}_{2}\right)$ gas. The concentrated DCM extract was used in the gas chromatographic analyses.

The same parameters were set for both GC-MS and GC-FID. The column was heated from $50^{\circ} \mathrm{C}$ to $280^{\circ} \mathrm{C}$ at $5^{\circ} \mathrm{C}$ per minute and the temperature held for $2 \mathrm{~min}$ at $280^{\circ} \mathrm{C}$. Mass spectra were scanned from 35 to $250 \mathrm{~m} / \mathrm{z}$. Normalization of the results was achieved through Kovát's indices generated from a series of $\mathrm{C}_{7}-\mathrm{C}_{40}$ saturated alkane standard mixture incorporated into the sample matrix and an equation for non-isothermal programs. The resulting peaks were identified by comparing the mass spectra with the NIST MS Search v 2.0 library.

\section{RESULTS AND DISCUSSION}

\section{Identification of desulfoglucosinolates}

Preliminary identification of specific GSLs was made by comparison of chromatograms with those obtained from previous works done on these compounds using identical parameters. UV-Vis determination of optimum wavelength was done using $230 \mathrm{~nm}, 214 \mathrm{~nm}, 254 \mathrm{~nm}$ and $280 \mathrm{~nm}$. The ideal working wavelength was found to be at 230 $\mathrm{nm}$ which showed absorbance of the GSLs being observed. The desulfoglucosinolates were identified on the basis of retention times and mass spectral analyses.

LC-MS analysis (Figures 2 and 3) of desulfosinigrin (1) (retention time or RT $8.2 \mathrm{~min}$ ) gave a peak at $\mathrm{m} / \mathrm{z} 302.0663$ which was conferred to the sodium adduct of the molecular ion $[\mathrm{M}+\mathrm{Na}]^{+}$, as well as a fragment at $\mathrm{m} / \mathrm{z} 280.0843$ which could be that of $[\mathrm{M}+\mathrm{H}]^{+}$. The most prominent peaks manifested were 149,177 and $245 \mathrm{~m} / \mathrm{z}$. The ion at $\mathrm{m} / \mathrm{z} 245.0782$ is proposed to be [glucose- $\left.\mathrm{NOH}-\mathrm{CH}_{2} \mathrm{CH}_{2}+\mathrm{H}+\mathrm{Na}\right]^{+}$produced upon rearrangement and loss of a $\mathrm{R}-\mathrm{C}=\mathrm{S}$ group as shown in Figure 4. The other peaks may represent ions obtained from the fragmentation of glucose. Cleavage of $\mathrm{R}-\mathrm{C}=\mathrm{NOH}$ from the molecular ion followed by the elimination of $\mathrm{H}_{2} \mathrm{O}$ is suspected to yield a thioglucose moiety $(177.0542 \mathrm{~m} / \mathrm{z})$. The fragment at $\mathrm{m} / \mathrm{z} 149.0228$ is also attributed to the fragmentation of glucose.

In red radishes, the constituent $\mathbf{2}$ at RT $12.7 \mathrm{~min}$ with the fragment $398.0858 \mathrm{~m} / \mathrm{z}$ was consistent with $[\mathrm{M}+\mathrm{Na}]^{+}$corresponding to 1,2-dihydroxy-2-phenylethyldesulfoglucosinolate. The mass spectrum of the constituent with an elution time of RT 13.7 min gave a fragment of $407.09130 \mathrm{~m} / \mathrm{z}$ and was construed to compound 3 . The retention time for 4-hydroxy glucobrassicin was substantiated from a previously reported work on desulfoglucosinolates. ${ }^{8}$

Compound 4 found at RT 15.7 min was the most prominent constituent in both white and red radishes. The mass spectrum of this compound indicated ions attributable to desulfoglucoraphasatin. $[\mathrm{M}+\mathrm{Na}]^{+}$was found at $362.06862 \mathrm{~m} / \mathrm{z}$ while that at $340.08674 \mathrm{~m} / \mathrm{z}$ could represent $[\mathrm{M}$ $+\mathrm{H}]^{+}$. The error $(-4.8)$ and mean error $(-4.4)$ values were lower than $+/-5$ ppm and mSigma fit (22.5) was less than 35 signifying a strong probability that the peak could be that of desulfoglucoraphasatin.

Constituent 5 was found at RT 17.6 min. Mass spectral analysis of this compound showed a fragment at $421.10406 \mathrm{~m} / \mathrm{z}$ which could be that of $[\mathrm{M}+\mathrm{Na}]$. Three prominent peaks were conspicuously present in the mass spectra of all compounds found in the radish extracts. The fragments, as presented in Figure 4 (e), with m/z 149, 177 and 245 could be used as diagnostic ions for desulfoglucosinolates analyzed by LC-MS in the positive mode.

\section{Myrosinase activity}

The results of our experiment showed that the thioglucoside glucohydrolase is active in radish tubers. The hydrolytic enzyme was found to be over 10 times more active in red tubers (2.05E-02 units) than in white radishes (1.55E-03 units). Although myrosinase activity has been well documented in white radishes, the decrease in enzyme activity could be attributed to losses associated with the removal of the peel in white tubers, which is common practice in culinary preparations, as reported by Nakamura, et al. ${ }^{10}$

\section{Identification of hydrolysis products}

Kissen, et al. ${ }^{11}$ stated that GSLs are converted to the corresponding aglycone by enzymatic hydrolysis with myrosinase (thioglucoside glucohydrolase, EC 3.2.3.1), which then decomposes to ITCs, thiocyanates, or nitriles, depending on the substrate, $\mathrm{pH}$ and availability of ferrous ions. In systems with physiological $\mathrm{pH}$, ITCs are the predominant products; while, acidic environments cause the formation of nitriles, as shown by Lambrix, et al. ${ }^{12}$ GSLs and myrosinase are segregated in intact plants. When this compartmentalization is lost by physical damage to plant tissue during freezing and thawing, chopping and chewing, myrosinase-catalyzed metabolism of GSLs occurs.

DCM extracts of freeze-dried white and red radishes were investigated by GC-EI-MS to detect the presence of preformed ITCs. In white and red radish extracts, one prominent peak was found at a retention time of 19.17 min (Figure 5) with a Kovát's index of 1430. The compound identification of 4-methylthio-3-butenyl isothiocyanate (6) was derived from the NIST library v. 2.0. Melchin, et al. ${ }^{13}$ specified that this specific

Red Tubers_RB4_01_58.d: UV Chromatogram, 214 nm

Figure 2: Total ion chromatogram of desulfoglucosinolates from red radish. 

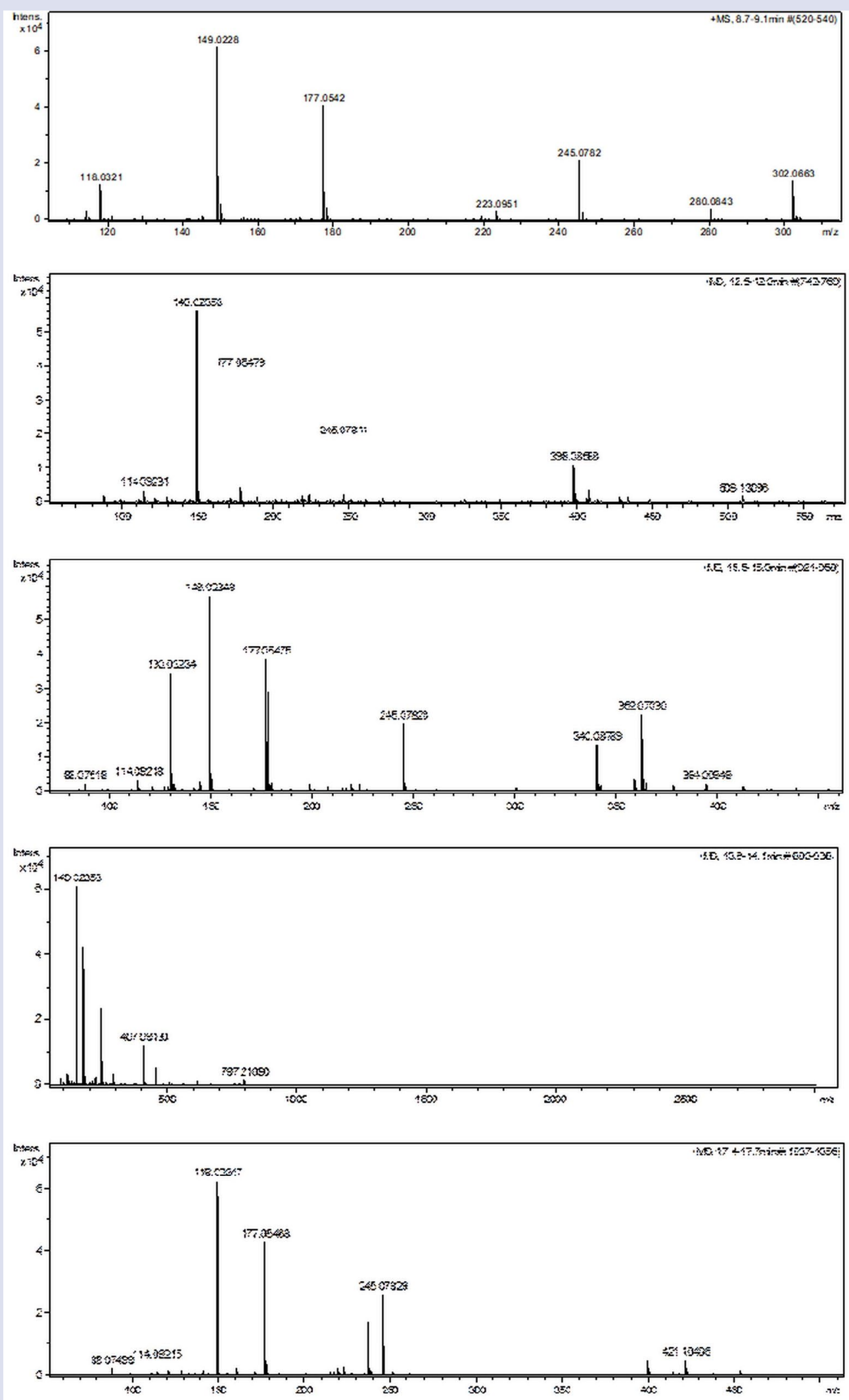

Figure 3: Mass spectrum of (a) desulfosinigrin; (b) desulfohydroxy-2- phenyl glucosinolate; (c) desulfo-4-hydroxy glucobrassicin; (d) desulfoglucoraphasatin; (e) desulfoneoglucobrassicin (a - e) - from top to bottom. 


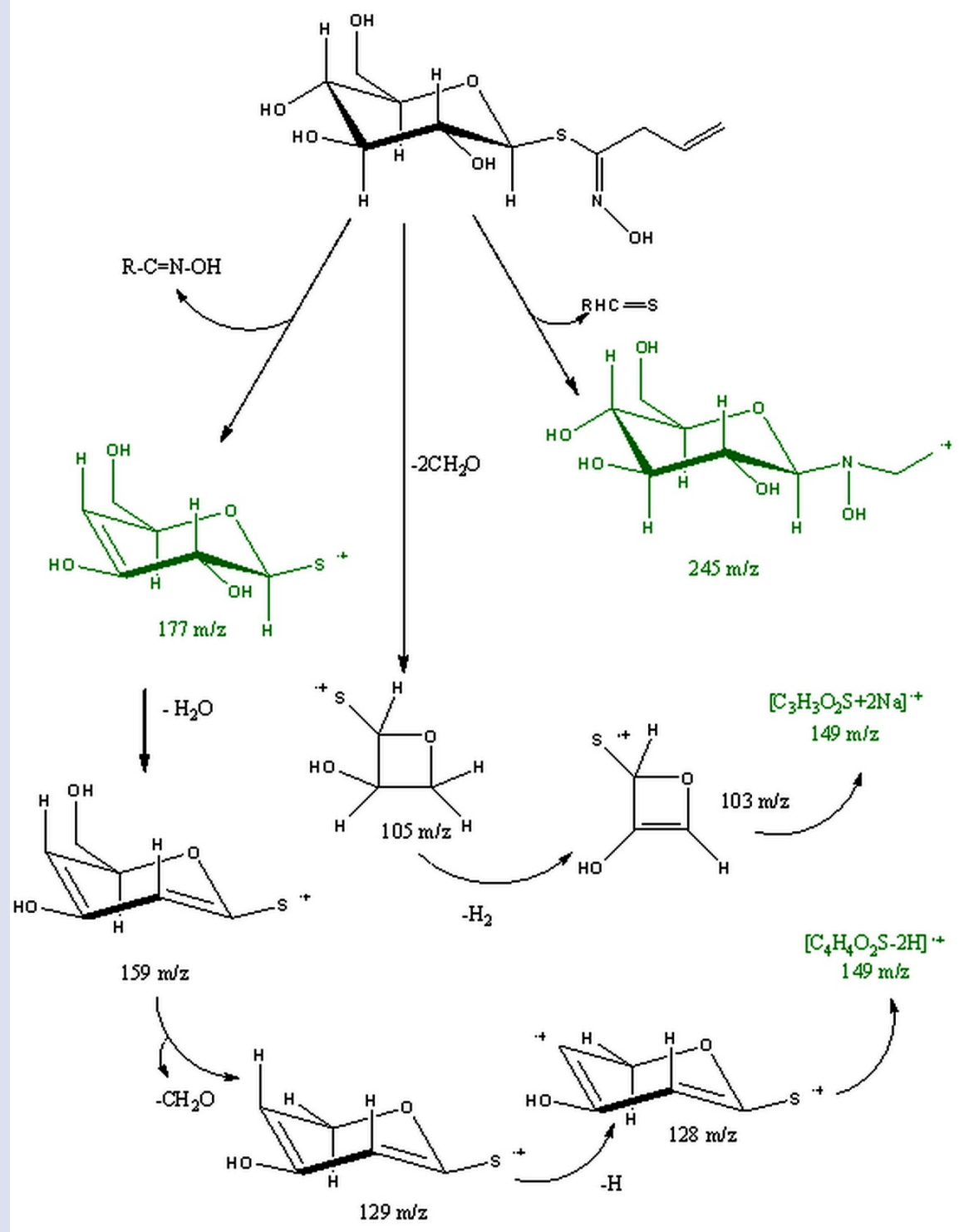

Figure 4: Proposed fragmentation of desulfoglucoraphasatin.

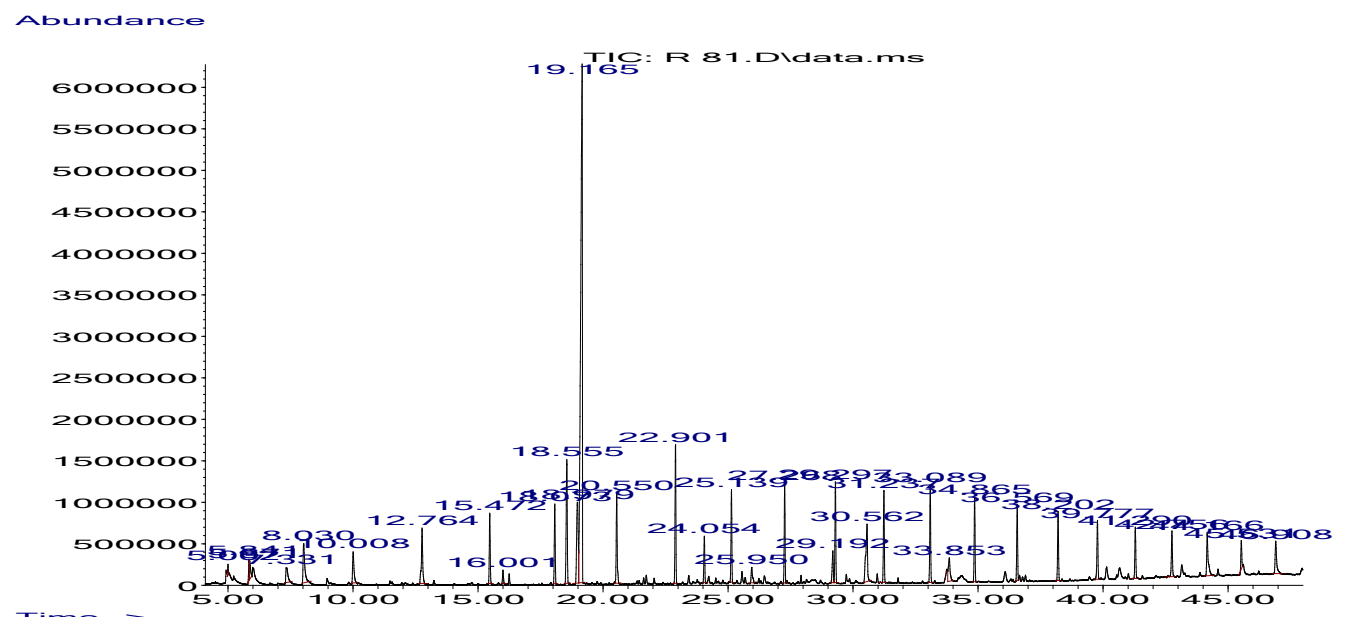

Figure 5: Total ion chromatogram of DCM extract of white radish homogenates. 
hydrolysis product was found to be a more effective bioactive agent than sulforaphane which is a well-known therapeutic compound.

Comparison with the GC-MS library showed the hydrolytic product 6 at $19.17 \mathrm{~min}$. The precursor ion or molecular ion was also the base peak which further authenticates the presence of this potential anticarcinogenic compound. The mass spectrum obtained from that peak is shown in Figure 6. The parent ion of the hydrolytic product at $\mathrm{m} / \mathrm{z}=$ 159 is consistent with the molecular formula $\mathrm{C}_{6} \mathrm{H}_{9} \mathrm{NS}_{2}$. Figure 7 shows the possible fragmentation pattern of ITC analog $\mathbf{6}$. The prominent peak with $\mathrm{m} / \mathrm{z}=87$ correlates to loss of $\mathrm{C}_{3} \mathrm{H}_{6} \mathrm{~S}$ (methyl thioethene) leaving the ethyl ITC ion. Further fragmentation causes the loss of a carbocation $(\mathrm{m} / \mathrm{z}=15)$ and the formation of the methyl ITC ion $(72$ $\mathrm{m} / \mathrm{z}$ ).

\section{CONCLUSION}

This work involved the characterization of GSLs and the determination of the hydrolysis products of extracts derived from tubers. Analysis for GSL content revealed that among the varieties available in the local market, red radish ( $R$. sativus cv.) had the highest levels of total glucosinolates followed by the white (daikon) (R. sativus L). variety. Sinigrin (1) and glucoraphasatin (compound 4) were found in white radishes and in red radishes, sinigrin (1). 1,2-dihydroxy-2-phenylethyl glucosinolate (glucosinolate 2), 4-hydroxy glucobrassicin (glucosinolate 3), glucoraphasatin (glucosinolate 4) and 4-methoxyglucobrassicin (glucosinolate 5) were identified through mass spectral analysis (positive mode, ESI QToF tandem MS). The hydrolytic enzyme was found to be over 10 times more active in red tubers $(2.05 \mathrm{E}-02$ units) than in white radishes (1.55E-03 units).

GC-MS analysis of dichloromethane extract of white radish gave a peak which was identified by mass spectral matching as constituent $\mathbf{6}$. The presence of endogenous $\beta$-thioglucosidase in both white $(1.55 \mathrm{E}-03$ units) and red (2.05E-02 units) cultivars enhanced the formation of the ITC analog which can be construed to the rearrangement of substrate 4. The implications of this extranutritional phytochemical, compound 6, from both red and white tubers have been linked to its bioactivity as an effective apoptotic agent in MCF-7 cell lines while showing minute signs of genotoxicity towards normal pulmonary endothelial artery cell lines. ${ }^{14}$

\section{ACKNOWLEDGEMENT}

The Commission on Higher Education Center of Excellence Research Grant is gratefully acknowledged.

\section{CONFLICTS OF INTEREST}

The authors have no conflicts of interest to declare concerning this work.

\section{ABBREVIATIONS}

DCM: Dichloromethane; GC-FID: Gas Chromatograph - Flame Ionization Detector; GC-MS: Gas Chromatograph - Mass Spectrometer; GSL: Glucosinolate; HPLC: High Performance Liquid Chromatography; ITC: Isothiocyanate; LC-ESI-QII-ToF- MS: High
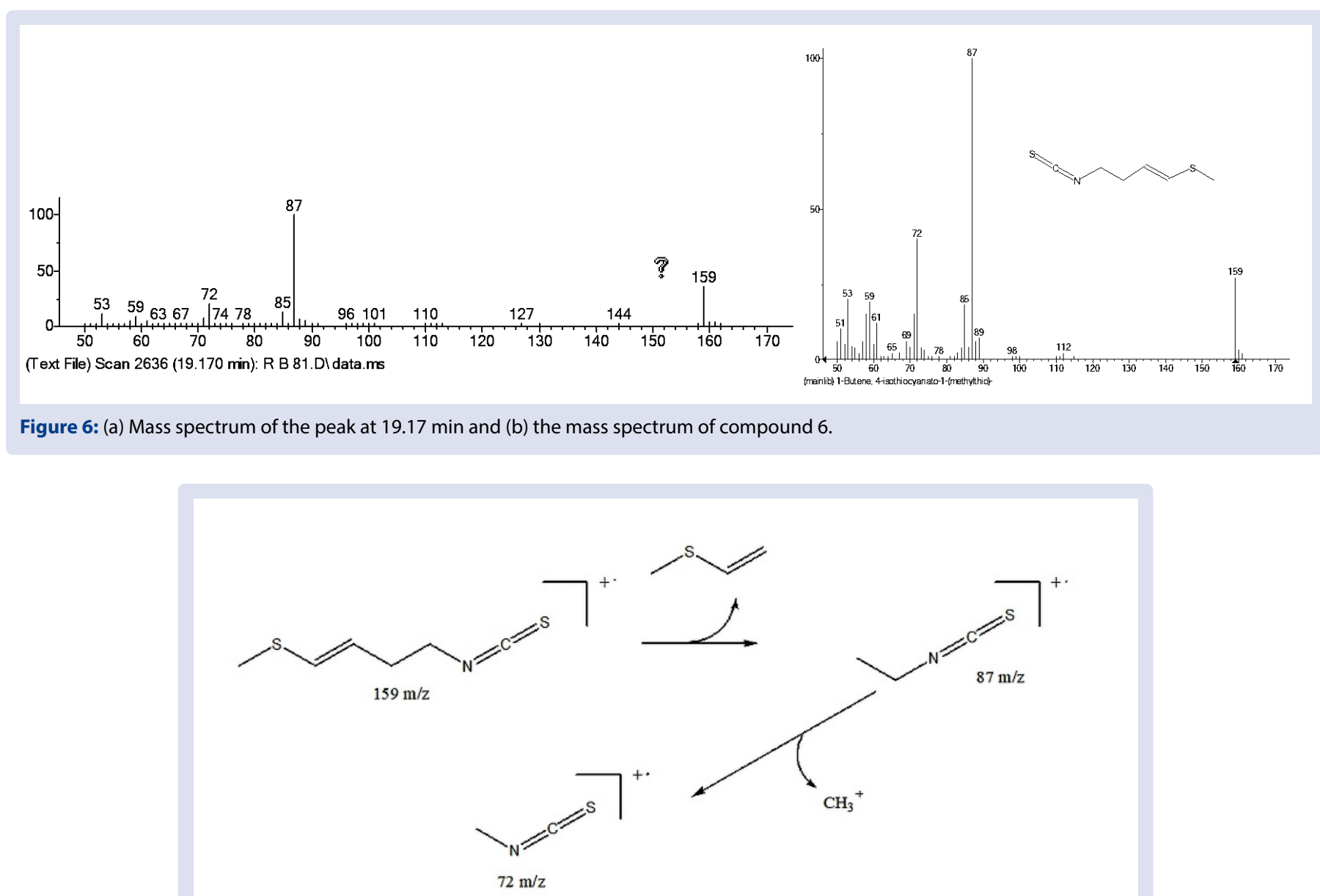

Figure 7: Fragmentation pattern of peak at 19.17 minutes. 
Performance Liquid Chromatograph - Electron Ionization - Double Quadrupole Time Of - Mass Spectrometer; $[\mathrm{M}+\mathrm{Na}]^{+}$: Sodium Adduct of Molecular ion; $[\mathrm{M}+\mathrm{H}]^{+}$: Proton Adduct of Molecular ion; RPC18: Reverse Phase Carbon Octadecyl Silane Column.

\section{REFERENCES}

1. Youlden DR, Cramb SM, Yip CH, Baade PD. Incidence and mortality of female breast cancer in the Asia-Pacific region. Cancer Biology \& Medicine. 2014:11:101-15.

2. Tommaso RI, Cataldi AR, Lelario F, Bufo SA. Naturally occurring glucosinolates in plant extracts of rocket salad (Eruca sativa L.) identified by liquid chromatography coupled with negative ion electrospray ionization and quadrupole ion-trap mass spectrometry. Rapid Commun. Mass Spectrom. 2007;21:2374-88.

3. Waser J, WatsonWH. Crystal structure of sinigrin. Nature. 1963;198(4887):1297-

4. Li Y, Chinni SR, Sarkar FH. Selective growth regulatory and pro-apoptotic effects of DIM is mediated by Akt and NF-kappaB pathways in prostate cancer cells. Front Biosci. 2005;10:236-43.

5. Oerlemans K, Barrett DM, Suades CB, Verkerk R, Dekker M. Thermal degradation of glucosinolates in red cabbage. Food Chem. 2006;95:19-29.

6. Carlson DG, Daxenbichler ME, VanEtten $\mathrm{CH}$. Glucosinolates in radish cultivars. J AMER Soc HaRT SCI. 1985;110(5):634-8.

7. Bell L, Wagstaff C. Glucosinolates, myrosinase hydrolysis products and elavonols found in rocket (Eruca sativa and Diplotaxis tenuifolia). J Agric and Food Chem. 2009;62:4481-92.

8. Bellostas N, Bjergegaard C, Jensen SK, Sørensen H, Sørensen JC, Sørensen S Nutritional value of cruciferous oilseed crops in relation to profile of accumulated biomolecules with especial regard to glucosinolate transformation products. 12th International Rapeseed Congress, Wuhan, China; 2007;25-8.

9. Palmieri S, Leoni O, lori R. A steady-state kinetics study of myrosinase with direct ultraviolet spectrophotometric assay. Anal Biochem. 1982;123:320-4

10. Nakamura Y, Nakamura K, Asai Y, Wada T, Tanaka K, Matsuo T, et al. Comparison of the glucosinolate-myrosinase systems among daikon (Raphanus sativus, Japanese white radish) varieties. J Agric \& Food Chem. 2008;56:2702-7.

11. Kissen R, Bones AM. Nitrile-specifier proteins ivolved in glucosinolate hydrolysis in Arabidopsis thaliana. J Biol Chem. 2009;284:12057-70

12. Lambrix V, Reichelt M, Mitchell-Olds T, Kliebenstein DJ, Gershenzon J. The Arabidopsis epithiospecifier protein promotes the hydrolysis of glucosinolates to nitriles and influences Trichoplusia ni herbivory. Plant Cell. 2001:13(12):2793807.

13. Melchin A, Traka MH. Biological profile of erucin: a new promising anticance agent from cruciferous. Toxins. 2010;2:593-612

14. Tan MCS, Enriquez MLD, Arcilla RG, Noel MG. Determining the apoptoticinducing property of isothiocyanates extracted from three cultivars of Raphanus sativus Linn. using the comet assay. J Appl Pharm Sci. 2017;7(9):44-51.

\section{GRAPHICAL ABSTRACT}

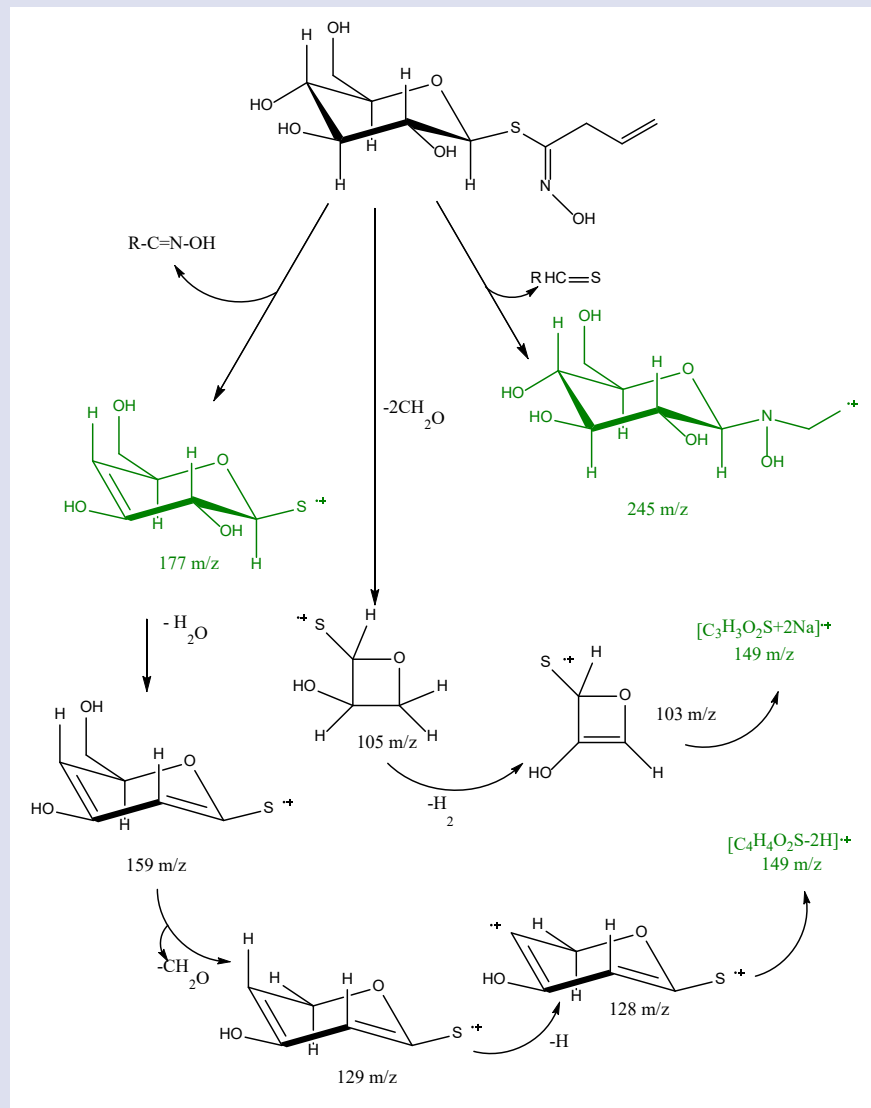

\section{SUMMARY}

Sinigrin and glucoraphasatin were found in white radishes and in red radishes, sinigrin. 1,2-dihydroxy-2-phenylethy glucosinolate, 4-hydroxy glucobrassicin, glucoraphasatin and 4-methoxyglucobrassicin were identified through mass spectral analysis (positive mode, ESI QToF tandem MS). The hydrolytic enzyme was found to be over 10 times more available in red tubers (2.05E-02 units) than in white radishes (1.55E-03 units). The presence of endogenous $\beta$-thioglucosidase in both white (1.55E-03 units) and red (2.05E-02 units) cultivars enhanced the formation of the 4-methylthio-3-butenyl isothiocyanate which can be construed to the rearrangement of substrate glucoraphasatin. The pharmacognosy of 4-methylthio-3-butenyl isothiocyanate has been associated as a chemotherapeutic agent.

Cite this article: Tan MCS, Noel MG. Glucosinolates, Degradation Products and Myrosinase Activity in Raphanus sativus Linn. Pharmacog J. 2019;11(5):866-72. 